\title{
Correção de fratura Salter-Harris tipo I em porquinho-da-índia (Cavia porcellus) - relato de caso
}

[Correction of Salter-Harris type 1 fracture in guinea pig (Cavia porcellus) - case report]

V.A. Silva, S. Wu, F.B. Fukushima, P.P. Adams, O. Cunha, R.J. Piccoli, A.L. Carvalho*

Hospital Veterinário - Universidade Federal do Paraná - Palotina, PR

\section{RESUMO}

Um filhote de porquinho-da-índia (Cavia porcellus) foi recebido para atendimento após histórico de ataque por cão. Na avaliação física, observou-se edema, dor e crepitação em membro pélvico direito, sugestivo de fratura. Na avaliação radiográfica, confirmou-se fratura Salter-Harris tipo I em epífise distal da tíbia. A resolução cirúrgica escolhida foi a associação de pino transarticular e coaptação externa com tala de Altman. O paciente teve acompanhamento radiográfico semanal e obteve alta médica no $35^{\circ}$ dia de póscirúrgico, quando se observou consolidação com completo remodelamento ósseo.

Palavras-chave: roedor, osteossíntese, transarticular, pino intramedular, tíbia

\begin{abstract}
A guinea pig (Cavia porcellus) cub presented edema, pain, and crepitus in the right pelvic limb after being attacked by a dog. Radiographic examination revealed Salter-Harris type 1 fracture on the distal region of the tibia. The surgery technique to correct the fracture involved an association of transarticular pinning and external coaptation with Altman splint. After surgery, radiographs of the patient were performed weekly and on the $35^{\text {th }}$ post-surgery day, the bone was completely remodeled and healed, and the animal was dismissed.
\end{abstract}

Keywords: rodent, osteosynthesis, transarticular, $k$-wire, tibia

\section{INTRODUÇÃO}

Afecções ortopédicas em pequenos roedores expressam grande importância na rotina de atendimento da clínica de animais exóticos de companhia. Nos roedores, em especial os jovens, as fraturas proximais ou envolvendo a linha fisária são um desafio à terapêutica, principalmente devido ao diminuto tamanho do paciente. Para correção de fraturas tibiais distais, em cães e gatos, algumas das técnicas empregadas são os pinos intramedulares e os pinos cruzados. Os primeiros são usados por interferirem pouco com a linha fisária, e os segundos têm seu emprego para pacientes próximos à maturidade, uma vez que comprimem a fise fraturada (Johnson e Hulse, 2002). Todavia nem sempre essas técnicas são aplicáveis a pequenos roedores, logo a adaptação de outras formas de redução é imprescindível. O presente trabalho relata o uso da associação de pino intramedular transarticular e da tala de
Altmann para correção de fratura de Salter-Harris tipo I em tíbia distal de um porquinho-da-índia (Cavia porcellus).

\section{CASUÍSTICA}

Foi recebido para atendimento um filhote de porquinho-da-índia (Cavia porcellus), macho, com aproximadamente três meses de idade, peso de $0,316 \mathrm{~kg}$ e histórico de ataque por cão no dia anterior ao atendimento. À inspeção física, o paciente não apresentava alterações clínicas dignas de nota, exceto claudicação em membro pélvico direito (MPD). Na avaliação ortopédica, observou-se edema, crepitação e dor em região distal de tíbia e fíbula direita. Após sedação com cloridrato de midazolam $(2,5 \mathrm{mg} / \mathrm{kg}$, IM) e sulfato de morfina $(1 \mathrm{mg} / \mathrm{kg}$, IM), o paciente foi encaminhado para estudo radiográfico, que revelou fratura completa na linha fisária tibial distal, com separação completa da epífise e metáfise (Fig. 1- A e B).

Recebido em 1 de dezembro de 2019

Aceito em 9 de junho de 2020

*Autor para correspondência (corresponding author)

E-mail: andersoncarvalho@ufpr.br 


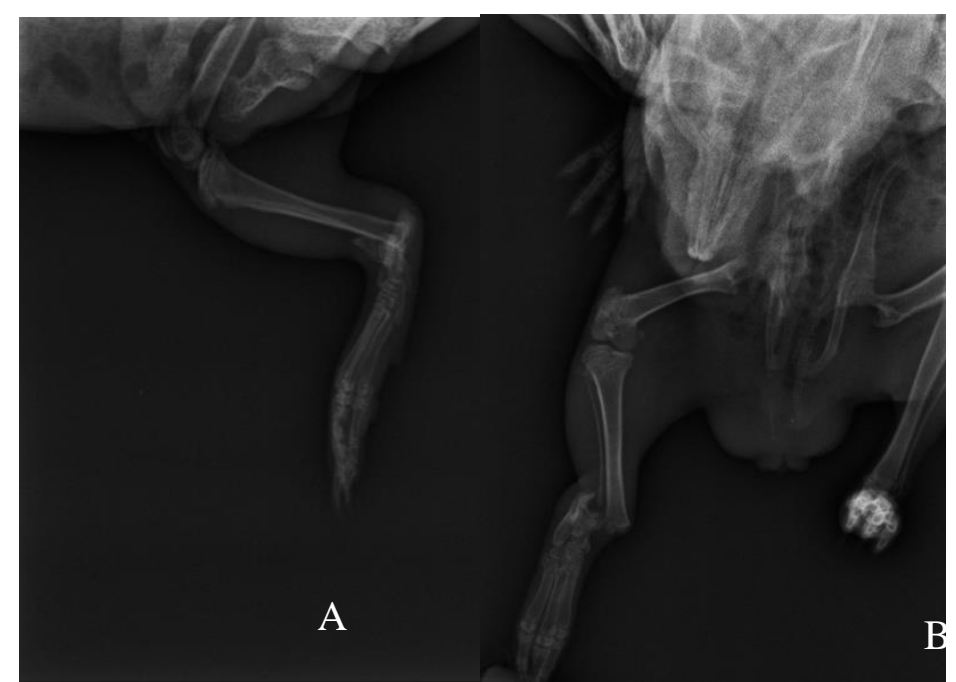

Figura 1. A - Radiografia pré-operatória, projeção mediolateral do membro pélvico direito de porquinhoda-índia. B - Radiografia pré-operatória, projeção craniocaudal do membro pélvico direito com evidência de fratura em linha fisária de tíbia distal.

Para controle da dor, utilizou-se cloridrato de tramadol $(10 \mathrm{mg} / \mathrm{kg}, \mathrm{SC})$, meloxicam $(0,5 \mathrm{mg} / \mathrm{kg}$, $\mathrm{SC})$ e dipirona sódica $(25 \mathrm{mg} / \mathrm{kg}, \mathrm{VO})$. A osteossíntese foi realizada no dia seguinte à chegada do paciente; para tanto, o paciente foi pré-medicado com associação de cloridrato de cetamina $(40 \mathrm{mg} / \mathrm{kg}, \quad \mathrm{IM})$ e cloridrato de dexmedetomidina $(0,25 \mathrm{mg} / \mathrm{kg}$, IM), seguida de indução e manutenção da anestesia com isoflurano em oxigênio a $100 \%$, em máscara facial, em concentração suficiente para manter plano anestésico cirúrgico, caracterizado por relaxamento muscular e ausência de reflexo palpebral, utilizando-se vaporizador calibrado. Após preparo do paciente para cirurgia asséptica, realizou-se redução fechada e manual da fratura, seguida da introdução de pino de Kirschner de 0,6mm de diâmetro, a partir do calcâneo em direção à metáfise proximal da tíbia, por via transarticular.

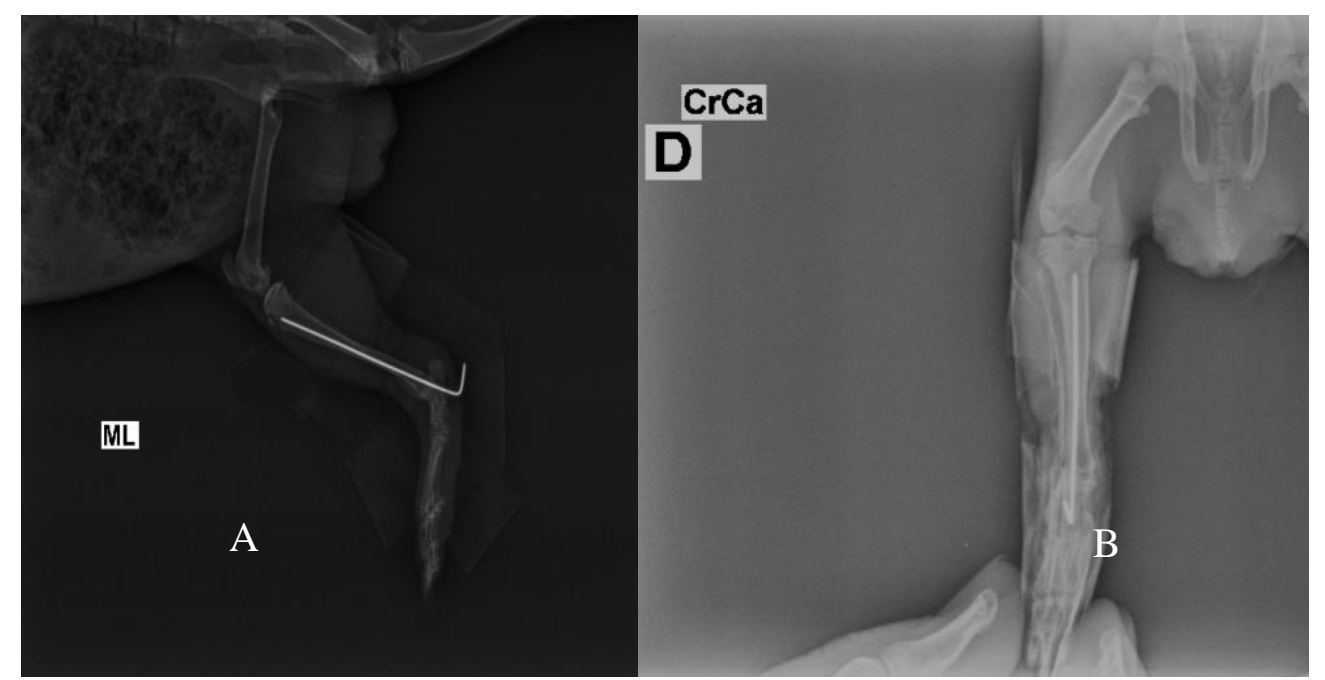

Figura 2. A - Radiografia do pós-operatório imediato, projeção mediolateral do membro pélvico direito de porquinho-da-índia após introdução de pino intramedular transarticular e tala de Altman. B - Radiografia do pós-operatório imediato, projeção craniocaudal do membro pélvico direito. 
Adicionalmente, adaptou-se a técnica de coaptação externa de Altman, via camadas de fita microporosa e esparadrapo alocado nas faces lateral e medial da articulação proximal e distal da tíbia, com o objetivo de garantir reforço adicional e redução das forças de rotação. Após o procedimento, foi realizada radiografia do pósoperatório imediato (Fig. 2 - A e B), que evidenciou adequado posicionamento do pino, alinhamento articular e aposição dos fragmentos.

O paciente foi liberado no dia seguinte, com prescrição domiciliar de dipirona suspensão $50 \mathrm{mg} / \mathrm{mL}(25 \mathrm{mg} / \mathrm{kg}$, BID, VO, por $10 \mathrm{dias})$, cloridrato de tramadol $50 \mathrm{mg} / \mathrm{mL}(10 \mathrm{mg} / \mathrm{kg}$, BID, VO, por sete dias) e probiótico (0,5g, BID, VO, por 10 dias). No retorno (dia 10, pós-cirurgia), o tutor relatou que o paciente havia removido a tala no dia anterior, e foi possível observar edema e secreção no local de inserção do pino. Para avaliação, o paciente foi sedado com cloridrato de midazolam $(2,5 \mathrm{mg} / \mathrm{kg})$ e sulfato de morfina $(1 \mathrm{mg} / \mathrm{kg})$, por via intramuscular, para realização de estudo radiográfico, que revelou foco de fratura alinhado em processo de cicatrização, com formação de calo ósseo.
Logo, prescreveu-se enrofloxacina $6 \mathrm{mg} / \mathrm{mL}$ $(7 \mathrm{mg} / \mathrm{kg}$, BID) e probiótico (0,5g, BID) via oral, por sete dias, e optou-se por manter o paciente sem tala. $\mathrm{O}$ retorno subsequente ocorreu no $13^{\circ}$ dia após cirurgia para nova avaliação radiográfica, quando o paciente foi sedado com cloridrato de midazolam $(2,5 \mathrm{mg} / \mathrm{kg})$ e sulfato de morfina $(2 \mathrm{mg} / \mathrm{kg})$ por via intraperitoneal. $\mathrm{O}$ estudo radiográfico revelou consolidação óssea, o que permitiu a retirada do pino intramedular transarticular.

O paciente retornou para casa com a prescrição anterior mantida e recomendação para restrição de movimento. No retorno após 18 dias de cirurgia, observou-se deambulação normal, com adequado apoio do membro no solo, e uma nova radiografia revelou perfeita consolidação óssea, com remodelamento e ausência de linha de fratura (Fig. 3 - A e B). O paciente passou por mais dois retornos, com acompanhamentos radiográficos e recebeu alta médica no $35^{\circ}$ dia de tratamento desde sua admissão.

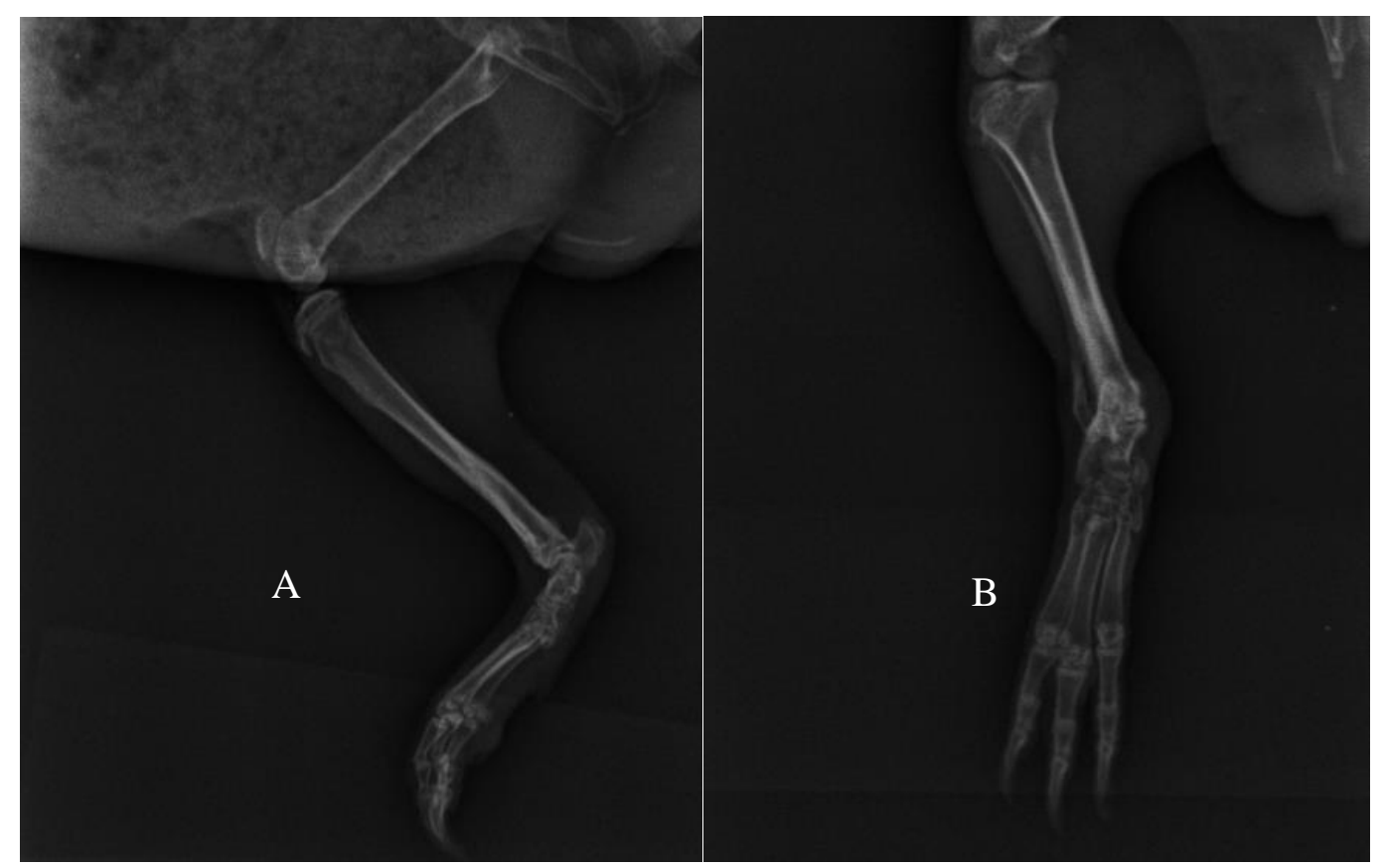

Figura 3. A - Radiografia do pós-operatório (dia 19), projeção mediolateral do membro pélvico direito de porquinho-da-índia após remoção do pino intramedular transarticular. B - Radiografia do pós-operatório imediato, projeção craniocaudal do membro pélvico direito após remoção do pino intramedular transarticular. 
Após 13 meses do procedimento cirúrgico, o paciente foi submetido a novas avaliações física, radiográfica e goniométrica do membro acometido, de forma comparativa com o membro contralateral (Fig. 4 A, B, C e D). As radiografias foram realizadas sem o uso de sedação, e o movimento articular foi promovido de maneira passiva, até o limite máximo permitido pelo paciente. Os dados de flexão e extensão de ambos os membros pélvicos estão descritos na Tab. 1 .
Tabela 1. Resultados referentes aos valores de amplitude de movimento em relação aos membros afetado e contralateral

\begin{tabular}{lcc}
$\begin{array}{c}\text { Amplitude de } \\
\text { movimento }\end{array}$ & $\begin{array}{c}\text { MPD } \\
\text { (afetado) }\end{array}$ & $\begin{array}{c}\text { MPE } \\
\text { (contralateral) }\end{array}$ \\
\hline Flexão & $104,4^{\circ}$ & $54,4^{\circ}$ \\
Extensão & $145,3^{\circ}$ & $153,2^{\circ}$ \\
\hline
\end{tabular}

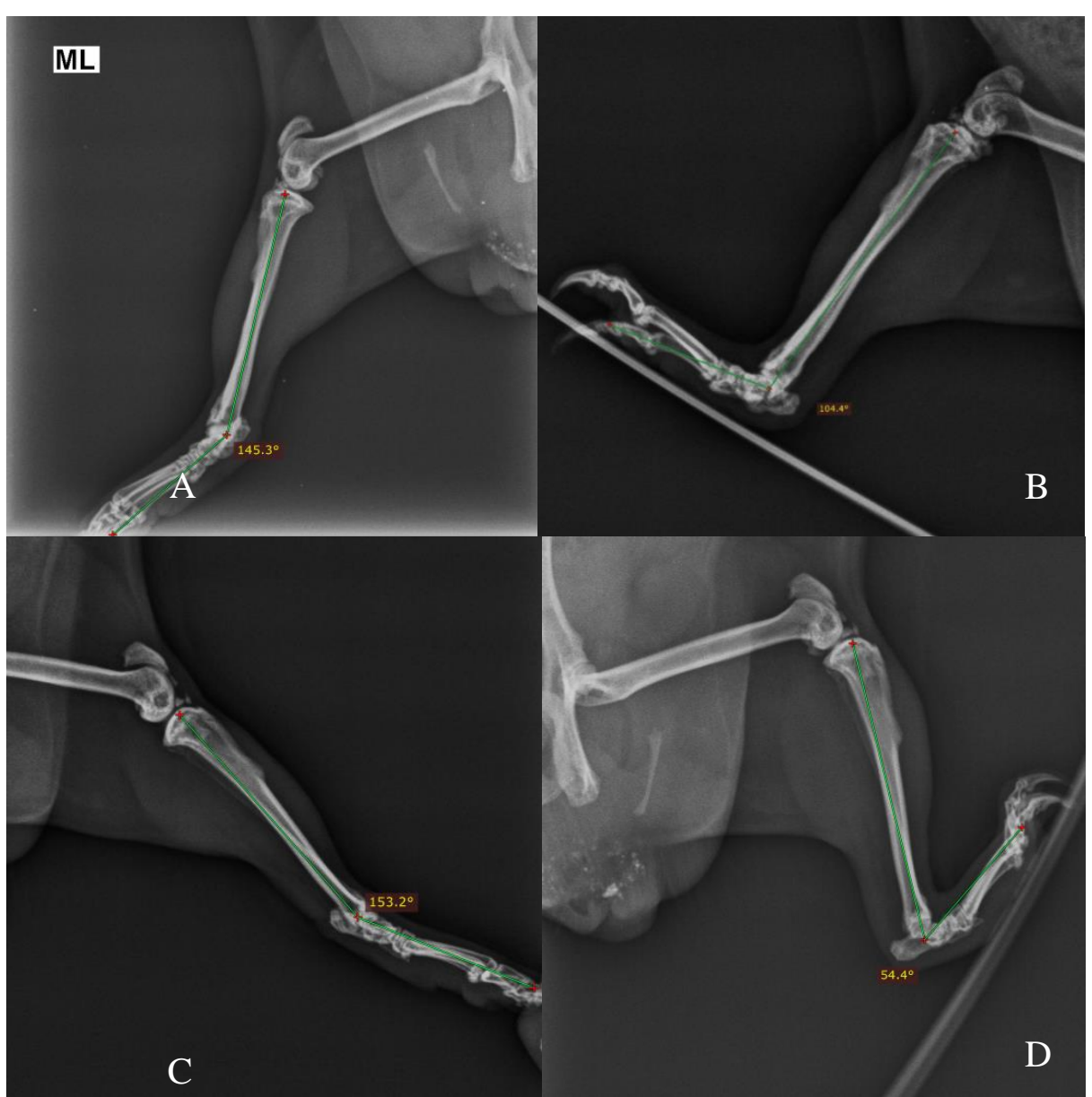

Figura 4. Radiografia 13 meses após osteossíntese. A - Projeção mediolateral do MPD de porquinho-daíndia com dado de extensão; B - projeção mediolateral do MPD de porquinho-da-índia com dado de flexão; C - projeção mediolateral do MPE de porquinho-da-índia com dado de extensão; D - projeção mediolateral do MPE de porquinho-da-índia com dado de flexão.

\section{DISCUSSÃO}

Traumas infligidos por ataques de outros animais estão entre as principais causas de fraturas em porquinhos-da-índia, nos quais são comuns as lesões em tíbia (Hawkins e Bishop, 2011). Na avaliação ortopédica, a sedação se fez necessária para diminuir a dor durante a manipulação, limitar o deslocamento dos fragmentos e garantir adequado posicionamento para o estudo radiográfico do membro afetado (Johnson e Hulse, 2002). A medicação pré-anestésica (MPA) tem como objetivos proporcionar manejo 
tranquilo, indução suave, diminuir o requerimento do anestésico inalatório e promover analgesia.

No presente caso, a associação de cloridrato de cetamina e cloridrato de dexmedetomidina promoveu sedação intensa e minimizou o estresse do paciente no período pré-anestésico, além de permitir indução tranquila via máscara facial e manutenção anestésica com baixa concentração de isoflurano. Nesse protocolo, como a cetamina não produz sedação e relaxamento muscular eficiente, a combinação com dexmedetomidina foi benéfica, pois conferiu intensa sedação, analgesia e relaxamento muscular com menores efeitos indesejáveis (Berry, 2017; Rankin, 2017).

Devido ao reduzido tamanho das vias aéreas e à maior dificuldade para intubação, optou-se pela manutenção anestésica com máscara facial, que, apesar da facilidade de aplicação, não assegura patência da via aérea e torna a monitoração respiratória e a manutenção do plano anestésico mais difíceis. Portanto, é importante a constante observação do padrão respiratório, como frequência respiratória e expansão do tórax, conforme se realizou nessa ocasião.

Nos casos de fraturas fechadas, recomenda-se o uso de antibioticoterapia pré-operatória, sendo uma dose (via intravenosa) a cada duas horas durante o transperatório (Hawkins e Bishop, 2011), o que não foi feito no paciente relatado, pois julgou-se tratar de uma cirurgia limpa, com duração total de 10 minutos. Porém, o mesmo apresentou secreção purulenta na região de inserção do pino alguns dias do pós-cirúrgico e, como não foi possível realizar cultura e antibiograma da secreção presente no local de inserção do pino para melhor escolha do antibiótico e caracterização do agente, prescreveu-se enrofloxacina, que se mostrou eficaz, sendo geralmente segura e com posologia estabelecida para a espécie (Hawkins e Bishop, 2011).

O escore de fratura do paciente deve ser considerado quando se realiza o planejamento cirúrgico, que avalia os quadros ortopédicos do ponto mecânico, biológico e clínico (Johnson e Hulse, 2002). O paciente atendido apresentava escore de fratura baixo, por se tratar de um paciente jovem, hígido, com fratura fechada e boa cooperação do tutor, fatores que promoveram maiores chances de sucesso na terapêutica. Em relação ao implante utilizado no paciente, os pinos intramedulares de Kirschner podem ser utilizados em fraturas fisárias em pequenos roedores (Hawkins e Bishop, 2011). Estes são eficazes para conter as forças de arqueamento que atuam sobre um foco de fratura, porém são insuficientes para tolerar as forças de torção (Johnson e Hulse, 2002; Hawkins e Bishop, 2011).

Dessa forma, optou-se pela associação de tala nesse paciente, o que corrobora o descrito por Hawkins e Bishop (2011) para os casos de utilização de pinos intramedulares isolados. A técnica de coaptação de Altman é usualmente empregada em fraturas de tibiotarso e tarsometatarso de aves e consiste em várias camadas de fita adesiva (esparadrapo ou micropore) dispostas sob as faces medial e lateral do membro, com incorporação das articulações proximais e distais da fratura (Hatt, 2008). A adaptação da tala consistiu no uso adicional de cola instantânea, entre as camadas de micropore, para garantir maior rigidez ao aparato. A técnica transarticular de introdução do pino se tornou mais adequada para o paciente devido ao seu tamanho e à dificuldade de se utilizarem outras abordagens, sendo a técnica primariamente descrita neste relato para a espécie, visando à redução desse tipo de fratura em tíbia, de acordo com a literatura consultada. A consolidação e o remodelamento ósseo ocorreram por volta do $21^{\circ}$ dia de terapêutica, o que é previsto e descrito para jovens caviomorfos (Macedo et al., 2015).

A avaliação da amplitude de movimento dos membros pode ser feita por meio da goniometria, que é um método prático de mensurar a mobilidade das articulações (Jaegger et al., 2002). A diminuição dessa amplitude pode ocorrer nos casos de utilização de aparatos de imobilização articular, contudo a remoção precoce desses normalmente minimiza essa perda (Jaegger et al., 2002). No presente caso, comparou-se também a amplitude de movimento, via mensuração radiográfica do membro afetado e do contralateral sob flexão e extensão. Os dados obtidos mostraram diminuição da capacidade de extensão e de flexão do membro afetado em comparação com o contralateral, entretanto essa diferença não foi significativa na avaliação clínica do paciente, cuja capacidade de deambulação foi preservada. 


\section{CONCLUSÃO}

$\mathrm{O}$ uso do pino intramedular transarticular associado à tala de Altman para correção de fratura de Salter-Harris tipo I se mostrou eficaz para o paciente atendido, sendo uma alternativa viável e de fácil aplicação, não descrita anteriormente em um espécime de porquinho-daíndia (Cavia porcellus).

\section{REFERÊNCIAS}

BERRY, S.H. Anestésicos Injetáveis. In: GRIMM, K.A.; LAMONT, L.; TRANQUILLI, W. (Eds.). Anestesiologia e analgesia em veterinária. 5.ed. Rio de Janeiro: Roca, 2017. p.271-290.

HATT, J.M. Hard tissue surgery. In: CHITTY, J.; LIERZ, M. Raptors, pigeons and passerine birds. Gloucester: [s.n.], 2008. p.157-175.

HAWKINS, M.G.; BISHOP, C.R. Disease problems of guinea pigs. In: QUESENBERRY, K.; CARPENTER, J.W. Ferrets, rabbits and rodents: clinical medicine and surgery. 3.ed. Philadelphia: Elsevier, 2011. p.295-310.
JAEGGER, G.; MARCELLINE-LITTLE, D.J.; LEVINE, D. Reliability of goniometry in Labrador Retrievers. Am. J. Vet. Res., v.63, p.979986, 2002.

JOHNSON, A.L.; HULSE, D.A. Fundamentals of orthopedic surgery and fracture management. In: FOSSUM, T.W. Small animal surgery. 2.ed. ST. Louis: Mosby, 2002. p.821-900.

MACEDO, A.S.; GOULART, M.A.; ALIEVIET, M.M. et al. Tibial osteosynthesis in a guinea pig (Cavia porcellus). Arq. Bras. Med. Vet. Zootec., v.67, p.89-93, 2015.

RANKIN, D.C. Sedativos e tranquilizantes. In: GRIMM, K.A.; LAMONT, L.; TRANQUILLI, W. Lumb \& Jones anestesiologia e analgesia em veterinária. 5.ed. Rio de Janeiro: Roca, 2017. p.188-198. 